\title{
New Probe into Problems of Earthquake and Energy Resources and Countermeasures
}

\author{
Du Wei-wen ${ }^{1}$, Ouyang Fan-fan ${ }^{1}$, Ouyang Zhong-Wan ${ }^{1}$ and Ou Shiyi ${ }^{2}$ \\ ${ }^{1}$ Hunan Agricultural University, Changsha 410128, China \\ ${ }^{2}$ Jinan University, Guangzhou, 510632, China \\ 582110392@qq.com
}

\begin{abstract}
Objective-This research attempts to explore reasons why the earth is divided into six sections, why at the junction of the plate is generally the area of strong earthquake activities and in the interior of a plate is generally safe, and what kind of the force drives the plate to move greatly and continuously. Method- Use diagnostic methods of traditional Chinese medicine for reference, such as inspection, auscultation, interrogation and palpation. Try to study the essence of the geographic phenomena by means of the observation, investigation, causes of the earthquake. Results- Generally speaking, the earth is made up of layers of different states and materials. Layers close to the earth surface in places where earthquakes erupt most frequently, namely the adjacent plates of the strong seismic activity areas, generally are in liquid, gaseous state or brittle solids. Most of these regions are rich in flowing oil, gas, fragile coal and other energy resources; however, those layers close to the earth surface in places where earthquakes seldom or have never erupted, namely the interior of a plate, generally are solid rocks, and their underground energy reserves are relatively low.

Index Terms - Earthquake, Energy, Problem, Countermeasure.
\end{abstract}

\section{Problem}

Recently series of earthquake occurred unceasingly has attracted worldwide attention. The earthquake is destructive. It can destroy houses, bridges, dams and other buildings immediately, and cause great disasters to human beings directly. It also evoked the flood, fire, tsunami, toxic and the leakage of radioactive materials and other secondary disasters. It lets a person feel the wrath of nature's awesome ${ }^{[1]}$. The cause of the earthquake has been a major topic of earthquake science, with the development of science and technology, people know the causes of earthquakes gradually. In 1915 German scientist Alfred Wegener first put forward the famous saying of continental drift, ushered in a revolution in the history of the earth science ${ }^{[2]}$. In 1960's further study of continental drift raised by American geologists R. Dietz (R.Dietz, 1961) who put forward the concept of seafloor spreading. Then, Hess (Hess, 1962) furthered the study that the ridge is where the new oceanic crust was born, which has laid the foundation for the rise of plate tectonics, and triggered a revolution in earth science.In 1968, French geophysicist Hide $\mathrm{O}$ (X. LePichon) put forward the theory of plate tectonics, the theory of plate tectonics, which is the integration and extension of the continental drift and the seafloor spreading theory. It is the most important academic achievement, known as a new revolution, and has made the research into causes of earthquake to step forward greatly ${ }^{[3]}$, but it still can not solve all the problems of crustal movement, such as why is the earth divided into six plates-the Pacific Ocean plate, the Eurasian plate, Africa plate Block, the American plate, India plate (Australia) and the Antarctic plate?why at the junction of the plate the earthquake activity is generally strong and the interior of a plate is generally safe?and what is the force driving plate to move greatly? Further study of continuous movement of the driving force and series of problems is needed ${ }^{[4]}$.

\section{Research Methods}

A. Useing diagnostic methods of traditional Chinese medicine for reference, such as inspection, auscultation, interrogation and palpation. Try to study the essence of the geographic phenomena by means of the observation, investigation, causes of the earthquake.

The nature is like a person, it is an organic whole, so is earth. Many natural phenomena will appear before the real natural disaster will occur. However, human beings can not find them all, and researches in this field are quite limited, let alone use these natural phenomena to service us. Continuely humen beings have to suffer from surprising attacks of nature. In face of natural disasters we are helpless most of the time, and are unable to forecast or take necessary measures to protect ourselves.

\section{B. Observational study}

Observe and study on crustal movement, such as the seismic, the gravity, the underground fluid and strong motion, $[5]$.

\section{Investigation and study}

Research into the data of the seismic geology, earthquakes, earthquake sites, earthquake prediction ${ }^{[5]}$.

\section{Analysis of the Results And Causes}

The earthquake is like wind, rain, lightning, is a rapid vibration of the earth's surface, called the earth movement in ancient China. The vibration of the earth is the most intuitive earthquake, the most common phenomenon. A strong earthquake occurred in the coastal area of the seabed or the seashore, can cause huge waves, called tsunami ${ }^{[6]}$. It is generally believed that the earth is made up of layers of different states and materials ${ }^{[7]}$. Layers close to the earth surface in places where earthquakes erupt most frequently, namely the adjacent plates of the strong seismic activity areas, generally are in liquid, gaseous state or brittle solids. Most of 
these regions are rich in flowing oil, gas, fragile coal and other energy resources. however, those layers close to the earth surface in places where earthquakes seldom or have never erupted, namely the interior of a plate, generally are solid rocks, and their underground energy reserves are relatively low.

According to the geological data, there are rich natural gas resources in Sichuan Basin, China, where the earthquakes broke out frequently. Causes of the earthquake are many, for instance, one of them is the late Yanshan - Himalayan tectonic movement, is easy to cause the gas to the migration ${ }^{[8]}$, accumulation along the fracture and crack, but one can not be ignored is that the mining of natural gas. If more gas resources are exploited, the earthquake will be more frequent and stronger, the destruction will be greater, the magnitude will be higher. When all the natural gas resources in Sichuan Basin are to be exploited one day, it is likely to collapse or sink into the lake.

Similarly, China's Bohai, the Yellow Sea -- Taiwan Strait -- the South China Sea, is situated in the bonding zone of Eurasian plate, Pacific plate and India - Australia plate, and belongs to the earthquake frequently outbreak area ${ }^{[9]}$, the part near the ground near is rich in liquid oil, if it is over mined, the space close to the ground which have been evacuated will become bigger, will be more frequent earthquake, and every time more strongly, destructive is more and more big, the magnitude will be higher. When one day all the oil resources in this area are to be exploited, this land and islands around it will collapse or sink into the sea.

As to Iran and Iraq in the Middle East, who are petroleum exporting countries, earthquakes occur frequently, and oil (liquid) was heavily mined, the space close to the ground evacuated will become bigger, will be more frequent earthquake, and every time more strongly, destructive is more and more big, the magnitude will be higher. When one day all the oil resources in this area are to be exploited, this land may exist no more.

In a word, over mining of the storage of natural resources will cause frequent earthquakes, because the pressure decreases after the liquid oil and gas have been exploited. Howerver, without expoitation, earthquakes happen as well because the pressure underground is too large and it will release too.

In addition, the part near the surface of the earth is liquid or gaseous. When the earth rotates, it will naturally produce a horizontal or vertical movement, and the force causing the horizontal or vertical movement will depend on whether this part is parallel with the equator or vertical to it. This hypothesis still needs more further srudies.

\section{Countermeasures}

A. Enhance knowledge of exploitation and exploiting rationally

Renew the idea of improving the knowledge of making the investigation and reducing the destrucion. The sense of responsibility and sense of urgency is important and necessary.
Implement the approach of "safety first, prevention first, comprehensive management" to realize the scientific prevention, to prevent us from new risks and create a safe, harmonious, stable social environment ${ }^{[10]}$.

In certain technical and economic conditions, we should use reasonable mining methods to exploit natural resources dynamicly, gradually master the rules and the characteristics of mining safely ${ }^{[11]}$, and slow down the exploitation of oil, gas, natural gas and other resources. In orderto keep the balance of the internal pressure of the earth, we can set up steel frames, fill in rocks or renewable material or slags(especially those slags, although they seem useless, they are one part of the chain of nature. The slags consciously buried not only can reduce the pollution, but also can be found useful by people one day. The soil and rocks of small hills nearby and movable groundwater can be used to fill in mined strata below too. Undeniably, the artificial vibration, such as human conflict or war, large ships, aircraft vibration, has great effect on the earthquake, we should also avoid wars, prevent or delay the occurrence of such accidents.

\section{$B$. To strengthen the supervision and inspection, to test the internal pressure underground regularly}

The safety supervision departments should strengthen the investigation, get rid of risks, carefully analyze the data, grasp the rules of the safe production, put forward countermeasures and suggestions, urge relevant departments to grasp factural conditions, improve the daily supervision and inspection, test the internal pressure regularly. Meanwhile, we should find problems in time by means of inspection, sampling, mutual inspection, etc ${ }^{[12]}$.

\section{Increase researches on new energy for environmental protection}

In order to develop renewable and clean energy, we should make our efforts to develop new green and alternative energies, such as nuclear energy, water energy, solar energy, geothermal energy, hydropower, wind and fecal energy, biological (plant) energy multifunctional utilization, so as to realize the substitution of those traditional energies. The supply of new energies can ease the pressure of pollution on the environment, meet the needs of human beings completely ${ }^{[13]}$.

\section{References}

[1] The Causes and Prevention of Earthquake and ItsSecondary Disasters: http://info.secu.hc360.com/list/ztxlb_002.shtml.

[2] Wegener Theory of Continental: http://baike.baidu.com/view/4275147.htm.

[3] Plate Tectonics: http://baike.baidu.com/view/62290htm.

[4] Theory-Baidu Encyclopedia: http://baike.baidu.com/view/1536773.htm.

[5] Earthquake: http://baike.baidu.com/view/781.htm.

[6] Isoseismal Line: http://baike.baidu.com/view/855645.htm.

[7] The Structure of the Earth: http://baike.soso.com/ v3917889.htm?sp=SST\%E5\%9C\%B0\%E7\%90\%83 $\%$ E7\%9A\%84\%Е6\%9E\%84\%Е9\%80\%A0

[8] Huang Junquan and Luo Zhili. "Strengthen the sichuan basin of shallow gas exploration is to solve the energy shortage is an important strategy 
for Sichuan,” J. Natural Gas Industry, Vol.15, no. 1, pp. 3-5, January 1995, China.

[9] Song Haibin, et al, "Researches on geophysical field characteristics and basement fault system of south China sea," J. Progress In Geophysics, Vol.17, no.1, pp. 24-33, March 2002,China.

[10] Investigation and Risk Management and Monitoring System of Job Responsibility: http://www.doc88.com/p-992239296676.html.
[11] Calculation of Geological Reserves of Oil and Natural Gas: http://www.chinabaike.com/z/yj/834584.html.

[12] State Production Safety Supervision and Management Administration Files: http://www.chinasafety.gov.cn/2008-02/20/content_273849.htm.

[13] Theme: energy,iatrogenic world. Forestry biomass energy: China's huge potential. Biomass energy, 2006-12-21. English text links refer to http://www.physorg.com/news11425.html. 